\title{
DIRECT ELECTRON HEATING WITH DIRECTIONAL FAST WAVE LAUNCH ON DIII-D
}

\author{
by \\ R.I. PINSKER, F.W. BAITY, S.C. CHIU, \\ J.S. deGRASSIE, C.B. FOREST, H. IKEZI, \\ M. MURAKAMI, C.C. PETTY, R. PRATER, \\ D.W. SWAIN, and THE DIII-D GROUP
}

DISTRIBUTION OF THIS DOCUMENT IS UNLIMITED 


\section{DISCLAIMER}

This report was prepared as an account of work sponsored by an agency of the United States Government. Neither the United States Government nor any agency thereof, nor any of their employees, make any warranty, express or implied, or assumes any legal liability or responsibility for the accuracy, completeness, or usefulness of any information, apparatus, product, or process disclosed, or represents that its use would not infringe privately owned rights. Reference herein to any specific commercial product, process, or service by trade name, trademark, manufacturer, or otherwise does not necessarily constitute or imply its endorsement, recommendation, or favoring by the United States Government or any agency thereof. The views and opinions of authors expressed herein do not necessarily state or reflect those of the United States Government or any agency thereof. 


\section{DISCLAIMER}

Portions of this document may be illegible in electronic image products. Images are produced from the best available original document. 


\section{DIRECT ELECTRON HEATING WITH DIRECTIONAL FAST WAVE LAUNCH ON DIII-D}

by

R.I. PINSKER, F.W. BAITY,* S.C. CHIU, J.S. deGRASSIE, C.B. FOREST, H. IKEZI, M. MURAKAMI,* C.C. PETTY, R. PRATER, D.W. SWAIN,* and THE DIII-D GROUP

This is a preprint of a paper presented at the 11th Topical Conference on Radio Frequency Power in Plasmas, May 17-19, 1995, Palm Springs, California, and to be printed in the Proceedings.

Work supported by U.S. Department of Energy Contracts DE-AC03-89ER51114 and W-7405-ENG-48

*Oak Ridge National Laboratory

\section{GENERAL ATOMICS PROJECT 3466 JULY 1995}




\title{
Direct Electron Heating with Directional Fast Wave Launch on DIII-D
}

\author{
R.I. Pinsker, F.W. Baity, * S.C. Chiu, J.S. deGrassie, \\ C.B. Forest, H. Ikezi, M. Murakami,* C.C. Petty, \\ R. Prater, D.W. Swain, ${ }^{*}$ and the DIII-D Group
}

General Atomics, San Diego, California 92186

*Oak Ridge National Laboratory, Oak Ridge, Tennessee 37831

\begin{abstract}
Direct electron heating obtained with a four-element array phased at $(0, \pi / 2, \pi, 3 \pi / 2)$ without a Faraday shield is compared with that obtained with a Faraday shield on the same antenna.
\end{abstract}

The potential advantages of Faraday shieldless fast wave antennas are well known: significant simplification of antenna designs with attendant reduction of costs, much easier and more reliable active cooling for longpulse operation, removal of an important source of $\mathrm{rf}$ sheaths, sputtering, and resulting impurities, and reduction of ohmic losses in the antenna structure. These advantages have led to a recent series of experiments in which the Faraday shield was removed from an existing antenna, and the resulting heating performance compared to an otherwise identical Faraday shielded antenna. Such experiments have been performed first on TEXTOR [1], and more recently on DIII-D [2] and on ASDEX Upgrade [3].

In most of the TEXTOR experiments and in all of the reported ASDEX $U$ results, the if power was absorbed at the hydrogen minority fundamental cyclotron resonance layer (high first-pass absorption), while the 1992 DIII-D shieldless results [2] were obtained with direct electron absorption using the toroidal antenna phasing of $(0, \pi, 0, \pi)$. In all three machines, satisfactory heating efficiency was obtained without the Faraday shield. In the present experiment, the directional phasing $(0, \pi / 2, \pi, 3 \pi / 2)$ was used, with similar target plasma temperatures as in the earlier experiment. Due to the higher parallel phase velocity of the launched fast waves, lower first-pass damping is expected than in the $(0, \pi, 0, \pi)$ case. Also, unlike the experiments on the other two machines, no special backup limiters or other measures were taken to minimize the plasma density at the radiating elements in the DIII-D shieldless antenna. These two factors make these experiments the most severe test of the shieldless antenna concept to date. 
The antenna array used for these experiments consists of four radiating elements, each $11 \mathrm{~cm}$ wide and $45 \mathrm{~cm}$ high, with the centerlines of the elements spaced $23 \mathrm{~cm}$ toroidally. The septum between elements ('straps') 1 and 2 and the one between 3 and 4 is behind the radiating surface, and hence these two septa do not affect the density at the strap surfaces. The septum between straps 2 and 3 and the edges of the two boxes in which the straps are mounted are $4 \mathrm{~mm}$ closer to the plasma than the front faces of the straps. The boxes are recessed into the port; the radial distance between the front edges of the boxes and the surface of the graphite tiles covering the vessel walls is $30 \mathrm{~mm}$. A poloidal backup limiter is located $23 \mathrm{~cm}$ to the right of the antenna. The surface of this limiter is raised $20 \mathrm{~mm}$ beyond the surface of the wall protection tiles. In this complex geometry, it is difficult to estimate the connection length that determines the plasma density at the strap surface in the shieldless case. However, the relatively long toroidal distance between the tiles on either side of the array $(98 \mathrm{~cm})$ implies a considerably longer scrapeoff distance than in the TEXTOR situation [1].

The Faraday shield used for comparison experiments consists of a single layer of Inconel rods $18 \mathrm{~mm}$ in diameter, spaced on $23 \mathrm{~mm}$ centers. The clearance between the front surface of the straps and the back surface of the shield rods was $7 \mathrm{~mm}$. The rods are slanted by $12^{\circ}$ to improve the alignment with the total static magnetic field, assuming the normal direction of plasma current and toroidal field in DIII-D. In these experiments, there was no protective coating on the plasma-facing side of the rods. Instead, it was hoped that the routine boronization of the vessel wall would provide an adequate coating in situ.

Since only a single antenna array was available for the comparison experiment, data were obtained on two experimental days separated by a vent to mount the Faraday shield. Identical wall conditioning procedures (boronization, baking, He glow conditioning between shots) were employed prior to and during each experiment in an effort to achieve identical conditions in both cases. The deuterium target plasma was a double null divertor $(R=174 \mathrm{~cm}, a=63 \mathrm{~cm}$, elongation $=1.9-2.1)$ with $I_{\mathrm{p}}=0.7 \mathrm{MA}$, a central toroidal field of $1.8 \mathrm{~T}$, and a line-averaged density of $1.1-1.3 \times 10^{13} \mathrm{~cm}^{-3}$.

From an operational point of view, the most obvious difference between the shielded and unshielded antenna was in the power handling. Despite generally lower antenna voltages in the unshielded case, the highest power level achieved in a full length pulse without antenna arcing was only about $0.8 \mathrm{MW}$, while as soon as the shield was reinstalled, reliable operation at 1.2 MW was quickly reestablished. Furthermore, there were no signs of improvement through conditioning during the period of shieldless operation. Rather, an apparent degradation in power handling was observed, so that by the time the shield was reinstalled, the reliable level of power had dropped below 0.5 MW. Signs of persistent arcing near the edges of the straps were observed during shieldless operation (video monitor, spectroscopy) and upon examination of the straps after the experiment. This arcing may be a result 
of higher plasma density at the strap surface without the shorter connection length provided by the shield.

Further evidence of higher plasma density in the antenna near fields in the shieldless case is obtained from observations of the antenna loading resistance. A significant nonlinearity in the loading is observed in the shieldless case which may be a result of rf sheath dissipation in the antenna near fields [4]; when the shield is in place, no such nonlinearity is observed over the same range of power levels under identical plasma conditions (Fig. 1). In the theory described in Ref. 4, the magnitude of the power dependent component of the antenna loading is proportional to the plasma density near the straps, so that the different behavior observed in the two cases indicates a higher density near the straps in the shieldless case. The disappearance of the anomalous loading at high power levels does not necessarily imply that the density at the strap has been reduced (by, for example, ponderomotive effects); such an effect is also produced by the different dependence of power dissipated in sheaths and power coupled to fast waves on antenna voltage.

The rise in the line-averaged density observed at turn-on of the rf power scaled approximately as $\Delta \bar{n}_{e} \sim P_{\text {net }}^{0.7}$, independent of whether a shield was present or not. The bolometrically determined radiated power losses were slightly larger without the shield than with the shield, though none of the monitored impurity lines were brighter in the shieldless case; no significant central radiation was observed in either case. The global heating efficiency was significantly better with the shield than without, as is apparent from Fig. 2(a). The incremental confinement time was nearly $40 \%$ greater in the shielded case. A corresponding difference was observed in the global absorption coefficient estimated from $d W_{\mathrm{p}} / d t$ at an abrupt rf turnoff: again, it appeared that the global power absorption was significantly better with the shield in place.

The most striking difference between the heating obtained with and without the Faraday shield with directional phasing was the very small increase in the central electron temperature observed in the shieldless case. This can be quantified in terms of the central electron heating effectiveness $\eta_{e}$, as defined in Ref. 5; the value of $\eta_{e}=20 \mathrm{msec}$ obtained from the shielded data in Fig. 2(b) is comparable to the values previously observed with $(0, \pi, 0, \pi)$ phasing and a double-layer Faraday shield [5]. However, without the Faraday shield

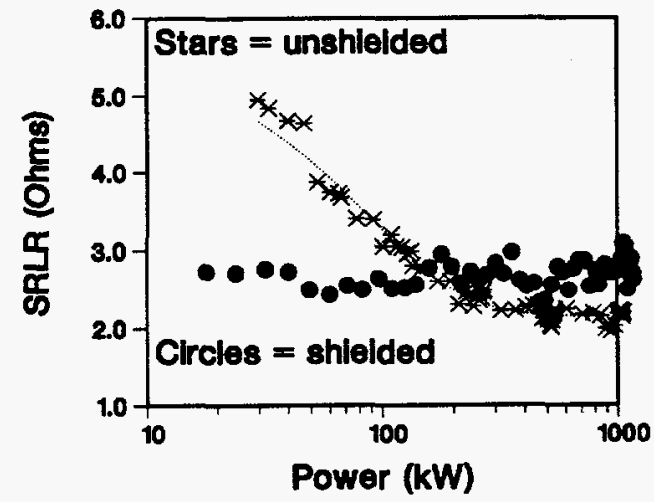

FIGURE 1. Series resonant load resistance as a function of net power applied to the antenna with a Faraday shield (filled circles) and without (stars). The dotted line is a fit to the shieldless data: $R=R_{0}+R_{1} \exp \left(-P_{\text {net }} / P_{c}\right)$, in which $R_{0}=2.15 \Omega, \quad R_{1}=3.6 \Omega, \quad$ and $P_{\mathrm{c}}=85 \mathrm{~kW}$. 
(a)

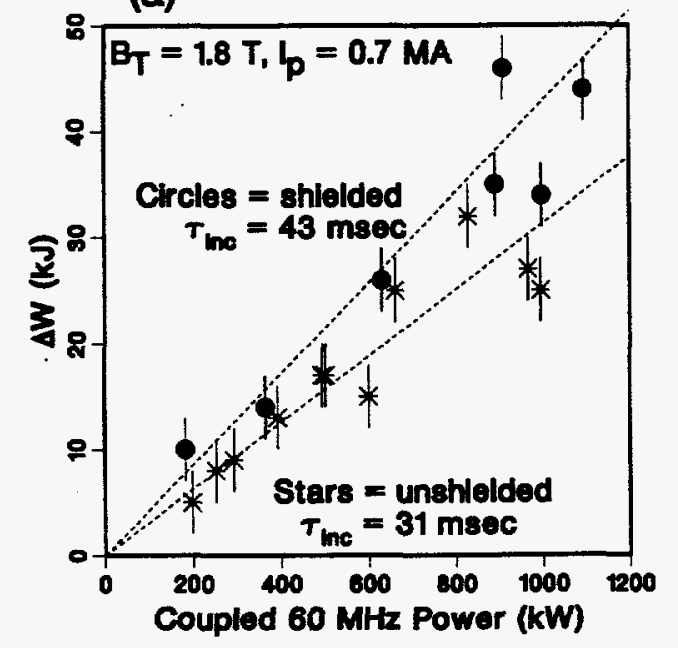

(b)

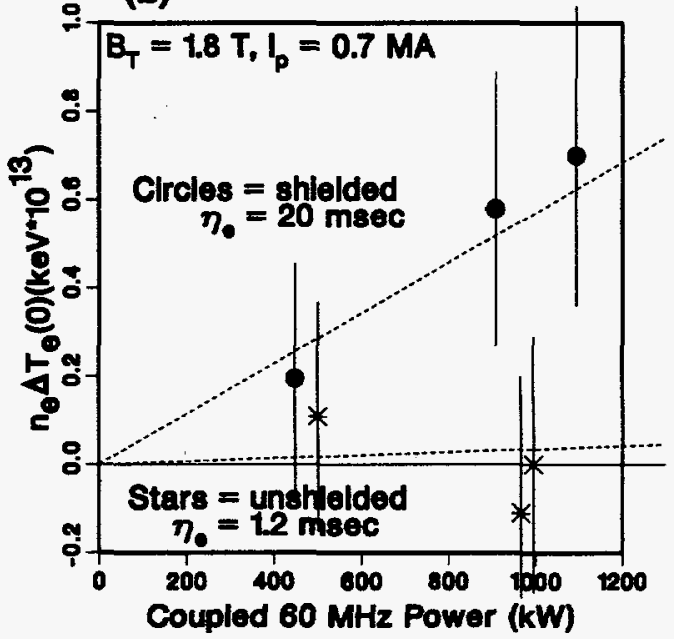

FIGURE 2. (a) Increase in plasma stored energy as a function of coupled if power with and without a Faraday shield. The average slope of each set of points (the incremental confinement time) is also indicated. (b) Increase in the central electron temperature normalized by the line-averaged density for the two cases. The slope multiplied by the plasma volume is the central electron heating effectiveness $\eta_{e}$, which has the units of time.

under otherwise identical conditions, $\eta_{e}=0$ within the experimental error. Even more remarkably, values of $\eta_{\mathrm{e}}$ as high as $40 \mathrm{msec}$ were observed in 1992 without a Faraday shield when $(0, \pi, 0, \pi)$ phasing was utilized [2]. These results point to an explanation in terms of a modification of the coupled fast wave spectrum: a shift to lower average $\left|n_{\|}\right|$due to a combination of ponderomotive effects and convective cells from the local rectified sheath potentials would cause degraded first-pass absorption in the shieldless case. The sensitivity of the central heating efficiency to the coupled spectrum is peculiar to direct electron heating with marginal target temperatures; good results without a Faraday shield in other heating regimes less sensitive to the coupled spectrum are not in contradiction to these results.

This is a report of work supported by U.S. DOE Contracts DE-AC0389ER51114 and DE-AC05-84OR21400.

\section{REFERENCES}

[1] Van Nieuwenhove, R., Koch, R., et al., Nucl. Fusion 32, 1913 (1992).

[2] Pinsker, R.I., Petty, C.C., et al., Bull. Am. Phys. Soc. 37, 1512 (1992).

[3] Noterdaeme, J.-M., et al., "Achievement of the H-mode ...," this conference.

[4] D'Ippolito, D.A., Myra, J.R., Lodestar Research Corp. Rep. LRC-95-52 (1995).

[5] Petty, C.C., Pinsker, R.I., et al., Phys. Rev. Lett. 69, 289 (1992). 